\title{
Chewing preference and its relationship with postural muscular electric potential
}

\author{
Klyvia Juliana Rocha de Moraes ${ }^{(1)}$ \\ Daniele Andrade da Cunha(1) \\ Lucas Carvalho Aragão Albuquerque (1) \\ Celina Codeiro de Carvalho(1) \\ Hilton Justino da Silva(1)
}

(1) Universidade Federal de Pernambuco UFPE, Recife, Pernambuco, Brasil.

Conflict of interests: Nonexistent

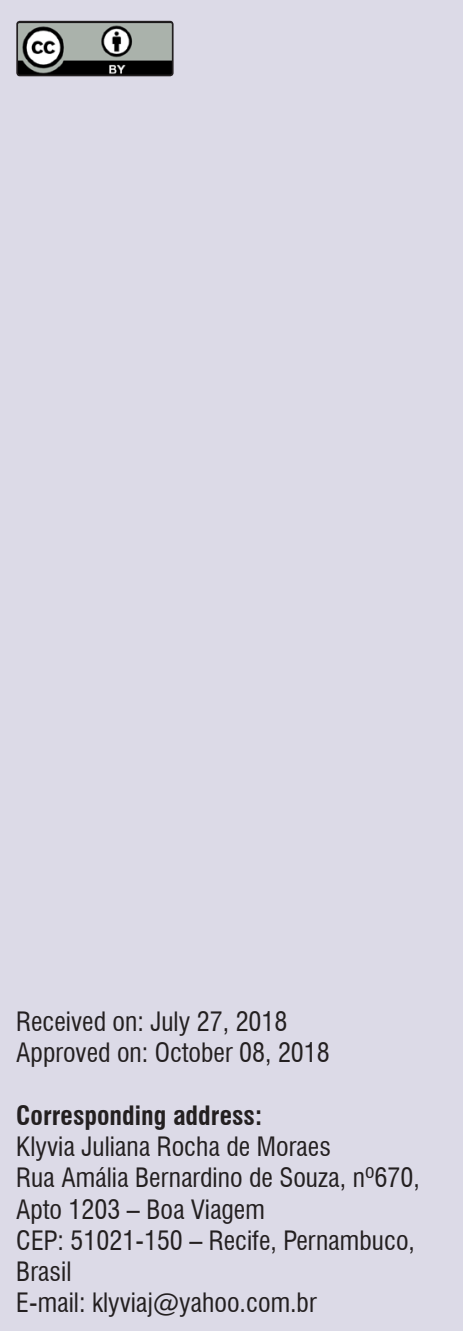

\section{ABSTRACT}

Objective: to verify if the chewing side preference interferes in the postural muscular electrical potential.

Methods: fifty-five volunteers ( 41 women and 14 men; average age of 26 years) were evaluated by Odontology (determining the type of dental occlusion), by a speech therapist (determining the chewing side preference) and by a physiotherapist (evaluating the postural muscular electrical potential). The three professionals had no communication regarding the evaluations, in order to keep the study partially blind. For chewing preference electrognatography was used for muscles: sternocleidomastoid, upper trapezium, gluteus medius and tibialis anterior, bilaterally, in static orthostatic posture.

Results: there was statistical significance for the muscular electrical potential of the sternocleidomastoid and anterior tibial, when there was right chewing preference $(p=0.030$ for both) and left chewing preference $(p=0.0028$ and $p=0.0020$, respectively). In alternate bilateral chewing there was tendency to symmetry of postural muscular electrical activation, in all muscles.

Conclusion: there was presence of asymmetry of postural muscular electrical activation in the sternocleidomastoid and tibialis anterior, when chewing side preference was at right or left. In the presence of alternate bilateral mastication, there was tendency of symmetry of postural muscular electrical activation for all studied musculatures.

Keywords: Chewing; Dental Occlusion; Stomatognathic System; Surface Electromyography 


\section{INTRODUCTION}

The chewing act seems to be a conditioned function, acquired and automatic, constituting a physiologic and complex act involving neuromuscular and digestive ${ }^{1}$ functions. Alternate bilateral chewing is considered as ideal by being responsible by the uniform distribution of strengths in the soft tissues and bones, providing stability and harmony due to the homogeneous distribution of the food between the right and left sides ${ }^{1-5}$.

It is believed that food consistency may favor individuals to stay with the so called, ideal mastication, or to choose a chewing side preference ${ }^{2}$. Thus, the customary and balanced mastication is seen more specifically and frequently in the forester man, due to the ingestion of harder and dry food ${ }^{6}$, while the man considered as civilized, has a tendency of more frequently having a chewing side preference, because it ingests more soft food, not enough to cause fatigue in one side of the mouth, resulting in the constant change of chewing side not being duly stimulated ${ }^{2,6}$.

For that, the presence of a chewing side preference increases the possibility of muscle misfits, because literature already mentions that different activities of the chewing muscles change the electromyographic signal of the cervical and postural muscles ${ }^{7,8}$. The investigation of the myoelectric potential in individuals with a chewing side preference gives the muscular response patterns while resting and during activities ${ }^{9,10}$.

Therefore, this research had as its intention, to verify if the existence of one chewing side preference, relates with the postural muscular electrical potential, represented by the sternocleidomastoid muscle, by the upper fibers of the trapezium, gluteus medius and anterior tibialis muscles, bilaterally.

\section{METHODS}

The research was approved by the Committee of Ethics and Research in Human Beings (CEP) from the "Universidade Federal de Pernambuco - UFPE", with record number: 715,051 and CAEE number: 30976214.5.0000.5208. A Free and Informed Consent Form (FICF) was subscribed, signalizing the voluntary agreement, after being oriented about the objectives of the study and being ensured about the confidentiality of information.

Volunteers were selected according to inclusion criteria: individuals from both sexes, aged between 24 and 45 years, normoclusion, that had no symptoms and/or temporomandibular restrictions and that were not in physiotherapeutic and/or phonoaudiological treatment.

The excluded volunteers were the ones using dental prosthetics; subjects with tooth loss; having ulcerative lesions of the oral cavity; that where submitted to surgeries in oral cavity or in head or neck; people with loss of oral sensibility; having structured scoliosis; with pain symptoms in knees.

The environment was kept silent and peaceful, with adequate luminosity and without excess of stimuli that could change the evaluation process. Fifty-five subjects (41 women and 14 men; average age of 26 years) were evaluated by Odontology in order to determine the type of dental occlusion; by speech therapy regarding the chewing side preference and by physiotherapy regarding the evaluation of the postural muscular electrical potential. Professionals had no communication about assessments, during their processing and interpretation in order to keep the study partially blind.

After interpretation by the evaluators, about their investigations and establishing the type of occlusion of the volunteer, by Odontology, being stratified as normoclusion, this volunteer was included in the research, provided that all the other already mentioned inclusions criteria were also contemplated.

Volunteers were also submitted to application of a questionnaire in order to obtain the Anamnestic Index of Fonseca et al. ${ }^{11}$, in order to discard the possibility of painful symptoms in temporomandibular joints and/or restrictions on them.

\section{Assessment of chewing side preference}

In order to collect data from the chewing preference an electrognatography was performed (JT-3D from brand BioRESEARSH $\left.{ }^{\circledR}\right)$. With the volunteer comfortably seated in a chair with backrest, a bread of $25 \mathrm{~g}$ was offered and the command given for the bite and chewing of a piece of this bread, during 20 seconds of test. The volunteer could not observe the graphic signal of those movements in the computer screen and had no visual stimuli from the mirror during the masticatory act.

Orientation for executing the chewing in the usual way was gave, without interference from the evaluator, regarding possible corrections in this action.

The movement of the magnet, located in the labial surfaces of the lower incisor teeth, captured the mandibular movement, as well as the amount of chewing cycles and their laterality. 


\section{Assessment of foot pressure and pressure center}

The protocol of electromyographic evaluation of the postural muscles was adapted from studies of Moraes et al. ${ }^{12,13}$. Before placing the surface electrodes, the skin was cleaned with cotton and $70 \%$ ethyl alcohol, in order to reduce impedance ${ }^{12-14}$. All electrodes had conductive gel.

The reference electrode was placed over the lateral epicondyle of the right humerus, in order to eliminate some interferences in the electric signal ${ }^{12,13}$. Distance between electrodes was settled at $1.5 \mathrm{~cm}$ for the studied muscle group ${ }^{12-14}$.

Electrodes were fixed in the middle point of the venter of each sternocleidomastoid muscle, longitudinally regarding their fibers ${ }^{12,13,15}$, four centimeters below the mastoid process, in order to avoid that fibers of the platysma muscle could create interferences ${ }^{16}$.

Regarding the upper fibers of the trapezium muscle, electrodes were placed at half the distance between the acromion and the spine of $\mathrm{C}$, longitudinally to their fibers, bilaterally ${ }^{12-14}$. For the gluteus medius muscle, electrodes were placed in the middle point between the iliac crest and the greater trochanter of the femur, bilaterally ${ }^{14}$.

For the anterior tibial muscle, the placement of electrodes followed the point of greater muscle volume, longitudinally to its fiber ${ }^{14}$. The orientation of the active electrodes followed the longitudinal disposition of the muscle fibers, in order to facilitate the capture of the muscular electrical potential ${ }^{12,13}$.

In order to reduce the discrepancies of the captured records ${ }^{17}$, with the volunteer in the bipedal posture, the muscle electrical signal was normalized, by means of the Maximum Resisted Voluntary Activity $\left(M_{R V A}\right)^{12}$, based on the muscle function tests ${ }^{18}$, for each muscle to be studied, as follows:

The contraction of the sternocleidomastoid muscle, flexing the cervical, manually resisted. The contraction of the upper fibers of the trapezium, requesting the simultaneous, maintained and resisted raise of the shoulders.

Still with the volunteer standing-up, and with anterior support, the contraction of the gluteus medius muscle was performed, Abducting the right lower limb in a manually maintained and resisted way (the same procedure reproduced to the contralateral side). For the anterior tibial muscle, with the volunteer seated, a dorsiflexion manually assisted was performed for the right ankle (the same procedure reproduced to the contralateral side).

Normalization was performed with 3 repetitions of 5 seconds of contraction for 10 seconds of relaxation, following the ratio of $1: 2^{12,13}$, the best of the three repetitions being chosen.

After normalization of EMGs signal, the stage called Nihil followed, with the volunteer standing-up, with the 8 channels connected to the electromyograph, capturing the EMGs signal from the postural muscles, during 1 minute ${ }^{12,13}$, with the volunteer in static position.

Tests Pearson's chi-squared, Mann-Whitney's as well as Kendall's tau b correlation coefficient for ordinal variables were used to compare parameters, according to chewing preference, being admitted value of $p<$ 0.05 in order to reject the null hypothesis attributable to chewing preference.

\section{RESULTS}

According to sample calculation, from the 55 evaluated volunteers, 30 had right chewing side preference; 9 had left chewing side preference and 16 had alternate bilateral chewing; there was no volunteer with simultaneous bilateral chewing or unilateral chewing (Table 1). Fifty-one volunteers had right-hand writing preference and only four had left-hand writing preference.

Table 1. Frequencies distribution of the chewing variable, in 55 volunteers

\begin{tabular}{ccc}
\hline Variable & Frequency & Percentage \\
\hline Right chewing preference & 30 & 54.5 \\
Left chewing preference & 9 & 16.4 \\
Alternate bilateral chewing & 16 & 29.1 \\
\hline
\end{tabular}


Comparing the postural muscular electrical potential with chewing preference, it was seen statistical significance for the muscular electrical potential of the sternocleidomastoid and of the tibial anterior, when there was right chewing preference $(p=0.030$ for both) and at left $(p=0.0028$ and $p=0.0020$, respectively) (Illustration 1 and 2).

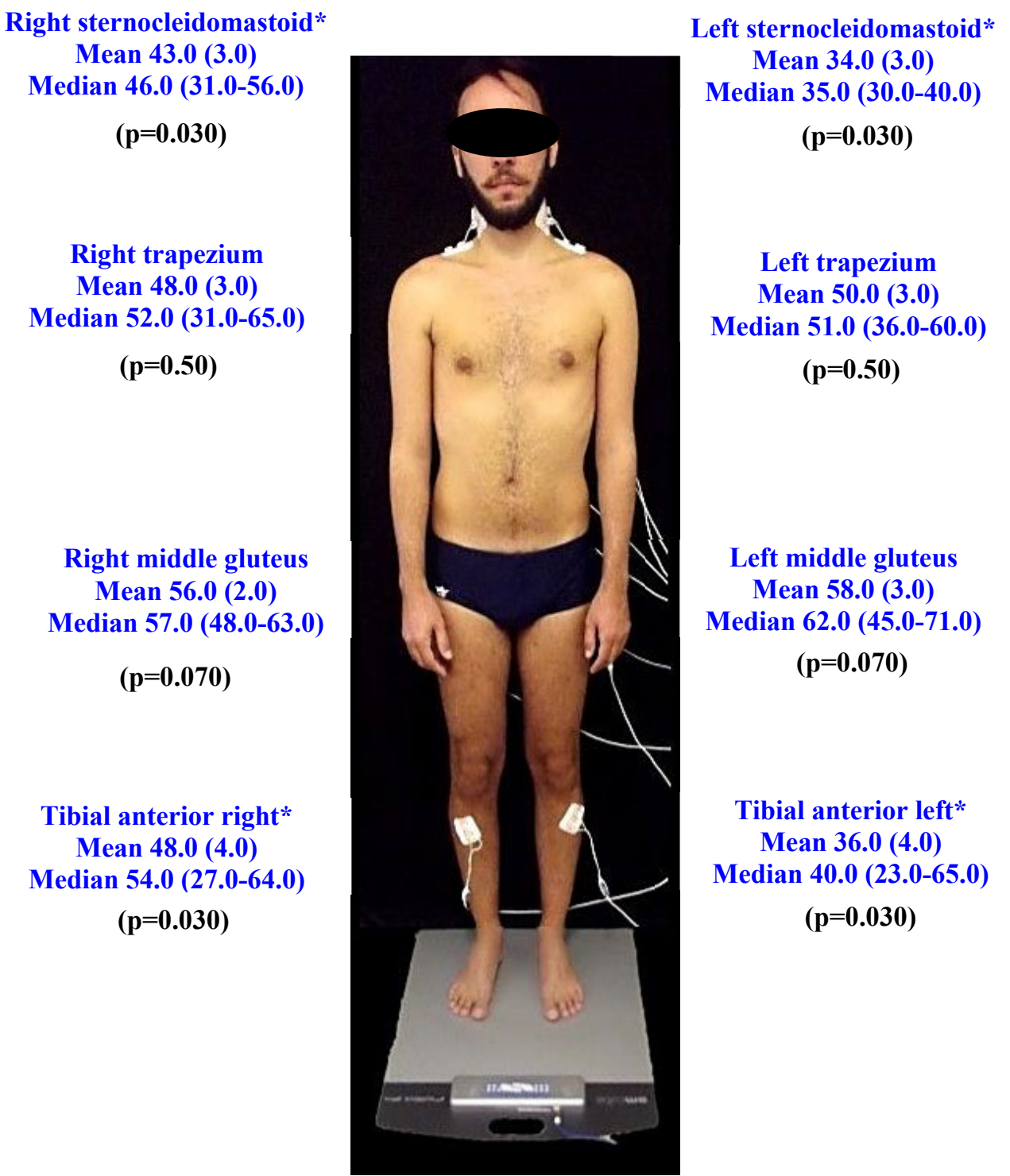

Legend: * Statistical significance

Illustration 1. Pictogram of means (standard errors of means) and medians of the electromyographic potentials according to right chewing preference. 


\section{Right sternocleidomastoid* \\ Mean $40.0(6.0)$ \\ Median 37.0 (30.0-45.0)}

$(p=0.0028)$

Right trapezium

Mean 48,0 (9.0)

Median 64.0 (24.0-70.0)

$(p=0.65)$

Right middle gluteus

Mean 44.0 (9.0)

Median 40.0 (30.0-41.0)

$(\mathrm{p}=\mathbf{0 . 7 0})$

Tibial anterior right*

Mean 27.0 (5.0)

Median 23.0 (18.0-32.0)

$(\mathrm{p}=\mathbf{0 . 0 0 2 0})$
Left Right sternocleidomastoid*

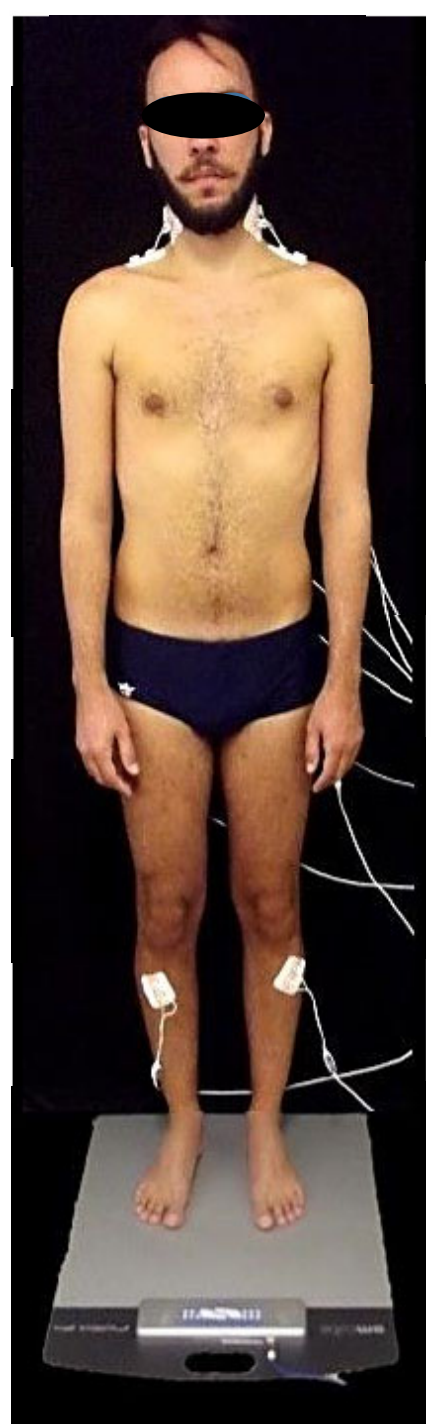

Mean 30.0 (5.0)

Median 29.0 (26.0-30.0)

$(p=0.0028)$

\section{Left trapezium}

Mean 49.0 (4.0)

Median 62.0 (57.0-63.0)

$(p=0.65)$

Left middle gluteus

Mean 45.0 (7.0)

Median 42.0 (32.0-43.0)

$(\mathrm{p}=\mathbf{0 . 7 0})$

Tibial anterior left*

Mean 36.0 (6.0)

Median 41.0 (17.0-47.0)

$(\mathrm{p}=\mathbf{0 . 0 0 2 0})$

Legend: * Statistical significance

Illustration 2. Pictogram of means (standard errors of means) and medians of the electromyographic potentials according to left chewing preference

When there was alternate bilateral chewing, it was identified, for all studied muscles, tendency to symmetry of postural muscular electrical activation, however, without statistical significance $(p=0.60$ for the muscular electrical potential of the sternocleidomastoid and alternate bilateral chewing; $p=0.54$ for the muscular electrical potential of the trapezium and alternate bilateral chewing; $p=0.50$ for the muscular electrical potential of the gluteous medius and alternate bilateral chewing and $p=0.067$ for the muscular electrical potential of the anterior tibial and alternate bilateral chewing) (Illustration 3). 


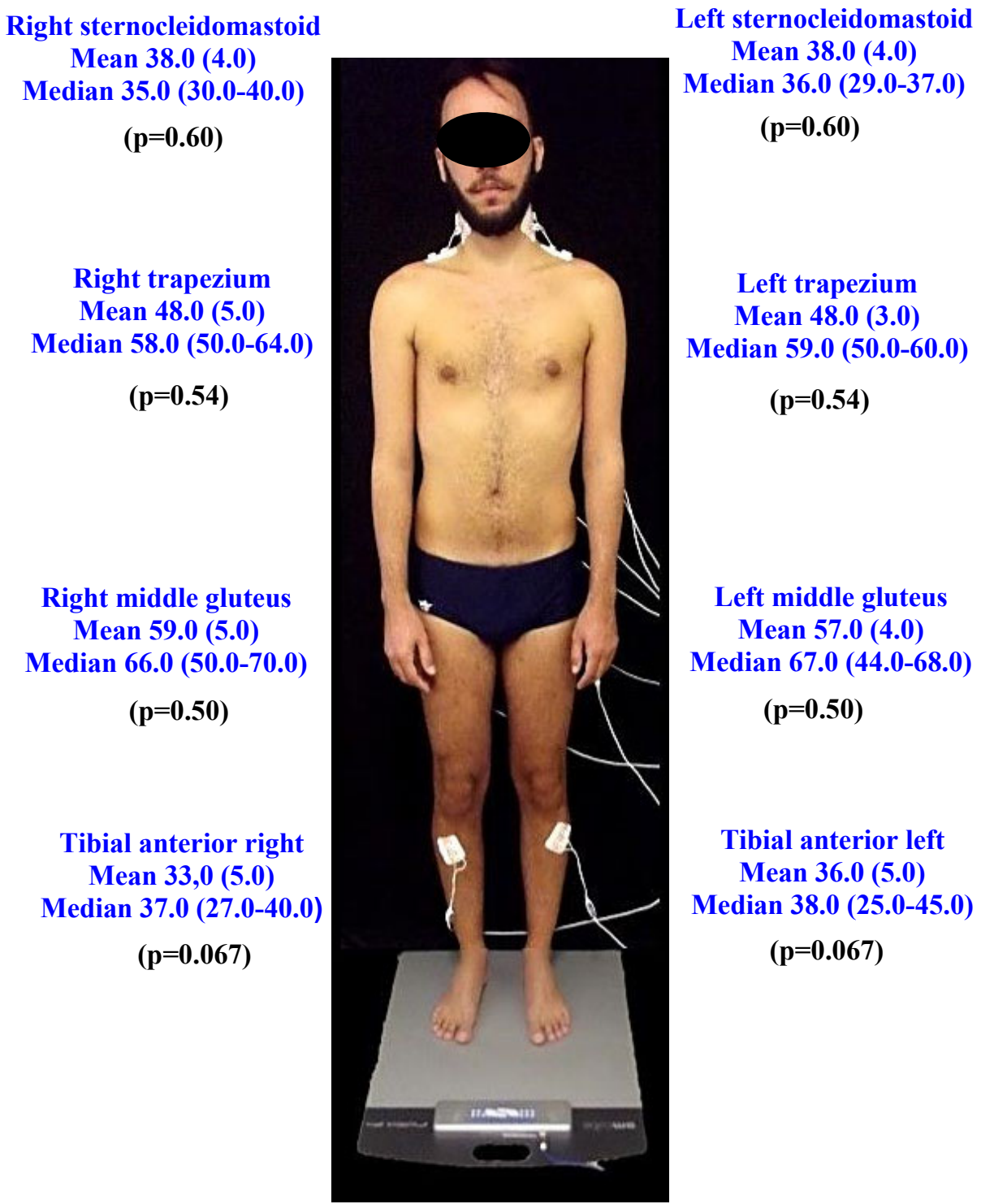

Illustration 3. Pictogram of means (standard errors of means) and medians of the electromyographic potentials according to alternate bilateral chewing.

\section{DISCUSSION}

It was seen that there was a greater quantity of volunteers with a right chewing side preference than with a left chewing side preference; and a greater frequency of right-handed individuals when compared to left-handed ones.

Studies show that, in statistic data, more than $90 \%$ of individuals have the right hand as the dominant; only $6 \%$ of individuals have the left hand as dominant and the remaining $4 \%$ are considered as ambidextrous ${ }^{19,20}$. A cerebral hemisphere being responsible by controlling the contralateral hand ${ }^{20}$.

Corroborating the findings of this research and the cited studies, literature points for the possibility of existing a relationship between brain dominance, writing dominance and the presence of a chewing side preference in individuals without complains and/ or temporomandibular restrictions since, it is believed in the determination of chewing side preference by the cerebral domination in this cases ${ }^{20,21}$.

The presence of a chewing side preference, in individuals without complains and/or temporomandibular restrictions is seen in literature as expected, possibly due to dietary change, with the advent of industrialization ${ }^{6,22}$.

Regarding the comparison of the chewing side preference and the postural muscular electrical potential, when chewing preference was at right, there was greater activation of the electric potential for the 
sternocleidomastoid muscle at left, as well as greater activation of the electric potential of the anterior tibial muscle at right, significantly. When there was left chewing preference, there was more activation of the muscular electrical potential for the sternocleidomastoid at right and greater activation of the muscular electrical potential for the anterior tibial at left, significantly.

In both cases of existing o a chewing side preference, there was asymmetry of muscular electrical activation for the sternocleidomastoid and for the anterior tibial muscle. For the other muscles (upper fibers of trapeziums and gluteous medius) there was tendency for a symmetry of muscular electrical activation, when there was right or left chewing preference, as well as a tendency at symmetry of the postural muscular electrical activation for all studied muscles (sternocleidomastoid, upper fibers of the trapeziums, gluteous medius and tibial anterior bilateral), when there was alternate bilateral mastication.

Justifying the electromyographic findings of asymmetries of muscular electrical activation when there is a chewing side preference, there is description of musculoskeletal imbalances secondary to the chewing preference, reflecting in one side with more muscle work when compared with the contralateral side; having the possibility of a functional impairment of the stomatognathic system, generating unbalance of strengths during the masticatory act, besides musculoskeletal misfits as well as misfits of the muscular electrical potential ${ }^{5}$.

This way, there may be a compensatory and adaptive process to the stomatognathic system ${ }^{23-26}$, suggesting that isolated conditions or ones restricted only to this system will not happen ${ }^{26}$.

In this sense, besides having this muscular masticatory hyperactivity, represented by the increase of muscular electrical potential, when the work is increased $d^{5,6,27}$, also characterizing the muscular electrical asymmetry and contributing with the electromyographic findings of the current research, there is also a tendency of misfits. This may happen in extraoral structures because the presence of neural connections between the cervical and trigeminal sensorimotor systems ${ }^{28}$, prove the strong neuromusculoskeletal and neurophysiological connections involved in the relationship between the orofacial, the cervical and other regions of the body, reinforcing the interdependence of the muscle chains of those regions ${ }^{26}$.

In this same line of reasoning of extra-oral alterations and muscle interdependence, some authors mention that the contraction of the masticatory muscles is associated with the increase of the electrical activity of the trapezium and sternocleidomastoid muscles, mainly in the existence of a chewing side preference ${ }^{7,8}$.

This information is partially cooperating with the current findings of asymmetry of myoelectric activation because there was, with the presence of a right or left chewing side preference, a greater muscular electrical activation of both the sternocleidomastoid and anterior tibial, however, for the trapezium there as symmetry of activation independently of having or not a chewing preference.

The cross-effect between musculatures having symmetry of muscular electrical activation and chewing side preference, in other words, of the right chewing preference with the greater myoelectric potential of the left sternocleidomastoid and right anterior tibial; left chewing preference with greater myoelectric potential of the right sternocleidomastoid and left anterior tibial, possibly existed due to the possibility of muscle compensation for trying to reestablish the postural muscle balance.

This may still be justified considering the relations between muscle chains with alterations in muscle dynamics, because it is seen that the proposal of the muscle chains considers the muscle system in an integrated way, aiming to rebuild the compensation chains installed in the body, in order to undo and dislodge the primary reason ${ }^{29}$. In the adaptive system, being represented by alterations of muscle activation, the function of the body and its structures will be to keep the balance as possible, in order to try to spend less energy to stay in that activity or posture ${ }^{29,30}$.

In contrast, the evident presence of symmetry of muscular electrical activation in all studied musculatures, in the presence of alternate bilateral mastication, is possibly due to the higher incidence of harmony and balance of the orofacial structures and the tendency of this harmony in an extra-oral way.

This information may be justified due to the physiology of chewing being characterized by alternate bilateral cycles, being an ideal condition for the functional concordance or the components of the stomatognathic system, characterizing a model of normality ${ }^{31}$, besides providing synchrony, stability, uniformity and balance of muscular contraction ${ }^{6}$.

\section{CONCLUSION}

It was seen that there was the presence of asymmetry of postural muscular electrical activation, 
in the sternocleidomastoid and anterior tibial, when there was right chewing preference. This myoelectric asymmetry was crosswise, when related with the chewing pattern, indicating the tentative of postural rebalancing.

In the presence of alternate bilateral mastication, there was tendency for symmetry of postural muscular electrical activation for all of the studied musculatures.

\section{REFERENCES}

1. Whitaker ME, Trindade-Júnior AS, Genaro KF. Proposta de protocolo de avaliação clínica da função mastigatória. Rev. CEFAC. 2009;1(3):311-23.

2. Amaral DB. Mastigação unilateral $x$ oclusão normal: um estudo sobre sua ocorrência em crianças de 4 a 5 anos. Rev. CEFAC. 2000;2:23-30.

3. Vieira RA, Lorio AP, Ferreira VJA. Características mastigatórias em crianças de 2 a 5 anos. Rev. CEFAC. 2003;5(1)59-62.

4. Douglas CR. Fisiologia da mastigação. In: Douglas $\mathrm{CR}$ (org). Fisiologia aplicada à fonoaudiologia. Rio de Janeiro (RJ): Guanabara - Koogan. 2006.

5. Nascimento GKBO, Lima LM, Freitas MCR, Silva EGF, Balata PMM, Cunha DA et al. Preference side masticatory and facial symmetry in total laryngectomy: clinical and electromyographic study. Rev. CEFAC. 2013;15(6):1525-32.

6. Pignataro-Neto G, Bérzin F, Rontani RMP. Identificação do lado de preferência mastigatória através de exame eletromiográfico comparado ao visual. R Dental Press Ortodon Ortop Facial. 2004;9(4):77-85.

7. Motoyoshi M, Shimazaki T, Sugai T, Namura S. Biomechanical influences of head posture on occlusion: an experimental study using finite element analysis. Eur J Orthod. 2002;24(4):319-26.

8. Catanzariti JF, Debuse T, Duquesnoy B. Chronic neck pain and masticatory dysfunction. Joint Bone Spine. 2005;72:515-9.

9. Paiva G, Mazzeto MO. Atlas de placas interoclusais. São Paulo: Santos. 2008.

10. Moraes KJR, Cunha RA, Lins OG, Cunha DA, Silva HJ. Eletromiografia de superfície: padronização da técnica. Rev Neurobiol. 2010;73(3):151-8.

11. Fonseca DM, Bonfate G, Valle AL, Freitas STF. Diagnóstico pela anamnese da disfunção craniomandibular. Rev Gaucha Odontol.1994;42:23-8.
12. Moraes KJR, Cunha DA, Bezerra LA, Cunha RA, Silva HJ. Surface electromyography: proposal of a protocol for cervical muscles. Rev. CEFAC. 2012;14(5):918-24.

13. Moraes KJR, Cunha DA, Cunha RA, Galvão ML, Silva HJ. Avaliação do sinal elétrico muscular cervical: proposta de um protocolo para os músculos esternocleidomastóideo e trapézio. In: Silva HJ (org). Protocolos de eletromiografia de superfície em fonoaudiologia. Recife: Pró- Fono; 2013. p.91-104.

14. Seniam. "SENIAM: European Recommendations for Surface Electromyography." [Acesso em: 13 nov 2016]; Available in: http:// www.seniam.org

15. De Luca CJ. The use of surface electromyography in biomechanics. J Appl Biomech. 1997;13:135-63.

16. Costa D, Vitti M, Tosello DO. Electromyographic study of the sternocleidomastoid muscle in head movements. Electromyogr and clin neurophysiol.1990;30(7):429-34.

17. Regalo $\mathrm{SCH}$, Vitti $M$, Oliveira AS, Santos $\mathrm{CM}$, Semprini M, Siéssere $S$. Conceitos básicos em eletromiografia de superfície. In: Felício $\mathrm{CM}$, Voi Treawitzki LV (org). Interfaces da medicina, odontologia e fonoaudiologia no complexo cérvicocraniofacial. São Paulo: Pró-fono, 2009. p. 31-50.

18. Kendall FP, McCreary EK, Provance PG. Músculos: provas e funções com postura e Dor. 4a ed. São Paulo: Editora Manole Ltda. 1995.

19. Kinsbourne M. Handedness. In: Adelman G (ed). Encyclopedia of neuroscience. Cambridge (MA): Birkhaüser; 1987. p. 19-20.

20. Herrmann MA, Ribeiro AG. Relação entre o lado preferencial da mastigação e a dominância cerebral. Rev. CEFAC. 2003;5:49-53.

21. Dultra CA. Preferência lateral mastigatória em indivíduos do sexo masculino [Dissertação]. Salvador (BA): Faculdade de Odontologia da Universidade Federal da Bahia; 1999.

22. Hoogmartens MJ, Caubergh MA. Chewing side preference during the first chewing cycle as a new type of lateral preference in man. Electromyogr Clin Neurophysiol.1987;27(1):3-6.

23. Krakauer LH, Guilherme A. Relação entre respiração bucal e alterações posturais em crianças: uma análise descritiva. R Dental Press Ortodon Ortop Facial. 2000;5(5):85-92.

24. Crispiano T, Bommarito S. Avaliação da musculatura orofacial e postura corporal em 
pacientes com respiração oral e mal oclusão. Rev da Odont. 2007;15:2-9.

25. Neiva PD, Kirkwood RN. Mensuração da amplitude de movimento cervical em crianças respiradoras orais. Rev Bras de Fisioter. 2007;11(5):355-60.

26. Mélo TMA, Carvalho CC, Cavalcanti AS, DouradoFilho MG, Pinheiro-Júnior PF, Silva HJ. Estudo das relações entre mastigação e postura de cabeça e pescoço: Revisão sistemática. Rev. CEFAC. 2012;14(2):327-32.

27. Oncins MC, Freire RMAC, Marchesan IQ. Mastigação: análise pela eletromiografia e eletrognatografia. Seu uso na clínica fonoaudiológica. Distúrb. Comun. 2006;18(2): 155-65.
28. Zafar H, Nordh E, Eriksson PO. Temporal coordination between mandibular and head-neck movements during jaw opening-closing tasks in man. Archives of Oral Biology. 2000;45:675-82.

29. Busquet L. As Cadeias musculares: tronco, coluna cervical e membros superiores. Edições Busquet: Belo Horizonte. 2001. Vol. 1. 1 edição.

30. Rodrigues CAC. Tratamento fisioterapêutico nas alterações de cadeias musculares pós cirurgia abdominotorácica. [Dissertação] Curitiba (PR): Universidade Tuiuti do Paraná, 2004.

31. Mory MR, Tessitore A, Pfeilsticker L, Couto-Júnior EB, Paschoal JR. Mastication, deglutition and its adaptations in facial peripheral paralysis. Rev. CEFAC. 2013;15(2):402-10. 